\title{
TIMP-1 and VEGF-165 serum concentration during first-line therapy of ovarian cancer patients
}

\author{
Sven Mahner*11, Linn Woelber ${ }^{+1}$, Christine Eulenburg², Joerg Schwarz'1,4, Walter Carney³ , Fritz Jaenicke1, Karin Milde- \\ Langosch $^{1}$ and Volkmar Mueller ${ }^{1}$
}

\begin{abstract}
Background: Angiogenesis appears to play an important role in ovarian cancer. Vascular endothelial growth factor (VEGF) has recently been implicated as a therapeutic target in ovarian cancer. The tissue inhibitor of metalloproteinase 1 (TIMP-1) is involved in tissue invasion and angiogenesis. The application of serum TIMP-1 and VEGF to monitor primary therapy and predict clinical outcome of patients with ovarian cancer is unclear.

Methods: Patients with epithelial ovarian cancer who presented for primary surgery were included in this study. A total of 148 serum samples from 37 patients were analyzed. Samples were prospectively collected at 4 predefined time points: 1. before radical debulking surgery, 2. after surgery and before platinum/taxane based chemotherapy, 3. during chemotherapy, 4. after chemotherapy. Serum VEGF-165 and TIMP-1 as well as CA-125 were quantified by ELISA or ECLIA and correlation with response and long-term clinical outcome was analyzed.

Results: Serum levels of all markers changed substantially during first-line therapy. High CA-125 ( $p=0.002)$, TIMP-1 ( $p$ $=0.007)$ and VEGF-165 ( $p=0.02)$ after chemotherapy were associated with reduced overall survival. In addition, elevated CA-125 $(p<0.001)$ and VEGF-165 $(p=0.006)$ at this time point predicted poor progression-free survival. TIMP1 and VEGF-165 were closely correlated at all time-points during therapy.

Conclusions: TIMP-1 and VEGF serum levels changed significantly during first-line therapy of ovarian cancer patients and predicted prognosis. These findings support the role of angiogenesis in ovarian cancer progression and the use of antiangiogenic therapy.
\end{abstract}

\section{Background}

Epithelial ovarian cancer accounts for the highest mortality among all gynecologic malignancies in the Western world. The American Cancer Society estimates more than 20.000 new cases and 15.000 deaths due to this disease each year in the United States [1]. Because of the absence of specific early symptoms most patients are diagnosed at an advanced stage with extensive intraabdominal disease and peritoneal carcinomatosis. Initial treatment for ovarian cancer consists of aggressive surgical cytoreduction and six cycles of carboplatin-paclitaxel combination chemotherapy [2]. Most patients will achieve radiologic and serologic complete remission after first-line therapy. However, $75 \%$ of these patients will

\footnotetext{
* Correspondence: Sven.Mahner@gmx.de

1 Department of Gynecology and Gynecologic Oncology, University Medical

Center Hamburg-Eppendorf, Hamburg, Germany

+ Contributed equally

Full list of author information is available at the end of the article
}

relapse and eventually die of their disease [3]. Clinical trials of the past decade have mainly focused on adding cytostatic agents to the established combination of carboplatin and paclitaxel to improve therapy. Unfortunately, this approach provided no benefit and development of new therapeutic strategies is required [4].

Enhanced understanding of the underlying biology of ovarian cancer has recently led to the discovery of molecular targeted therapies to accompany chemotherapy and potentially improve outcome [5]. Currently, angiogenesis appears to be the most promising therapeutic target for ovarian cancer [6-9] and large phase III trials with antiangiogenic therapeutics are conducted worldwide. In this context, the development of predictive and prognostic markers to optimize the use of these targeted approaches in clinical practice is one of the most important issues. Established prognostic factors in patients with epithelial ovarian cancer are International Federation of Gynecol- 
ogy and Obstetrics (FIGO) stage, residual tumor volume after primary surgical cytoreduction, tumor grading and histological subtype [10]. Several other clinical and biological factors including serum cancer antigen 125 (CA125 ) have been assessed for prognostic and predictive relevance $[11,12]$.

CA-125 is a high molecular weight glycosylated membrane protein that can be detected in serum and is elevated in more than $80 \%$ of patients with ovarian cancer. It is used as a marker to assess therapy-response and progression $[13,14]$. A rapid decrease of CA-125 during chemotherapy predicts a favourable prognosis and might also serve as a marker for disease recurrence. However, $20 \%$ of ovarian cancers have low or no expression of CA125 , thus, additional serum markers are required.

Degradation of basement membranes and extracellular matrix as well as neovascularisation are essential features in the progress of ovarian cancer. Vascular endothelial growth factor (VEGF) and tissue inhibitor of metalloproteinase-1 (TIMP-1) are involved in these processes and might therefore serve as potential biomarkers in ovarian cancer patients $[15,16]$.

The aim of the current study was to evaluate the role of serum VEGF-165 and TIMP-1 to monitor therapy and predict clinical outcome in patients with ovarian cancer in comparison to established clinicopathological parameters and CA-125.

\section{Methods}

\section{Patients}

Patients with epithelial ovarian cancer who presented for primary surgery at the University Medical Center Hamburg-Eppendorf between 1996 and 2004 were included in this study. A total of 148 serum samples from 37 patients were analyzed. Detailed patient characteristics are listed in Table 1. Clinicopathologic factors were evaluated by reviewing medical charts and pathological records. Tissue slides were reviewed for histological classification and clinical outcome was followed from the date of surgery to the date of death or until the end of 2007. Response to therapy was evaluated with the biomarker CA-125. All patients gave written informed consent to access their tissue/serum and to review their medical records according to our investigational review board and ethics committee guidelines. The use of medical records, serum and tumor tissue was approved by the ethics committee of the Medical Board Hamburg (reference number \#190504).

\section{Serum samples}

Serum samples were collected at 4 predefined timepoints: 1 . before surgery (within 7 days before surgery); 2 . after surgery (within 7 days after surgery) and before chemotherapy; 3. during chemotherapy (within 3 weeks of the third cycle of chemotherapy); 4 . after chemotherapy
Table 1: Patient characteristics

\begin{tabular}{cc}
\hline No. of patients & 37 \\
\hline Age (years) & 58 \\
\hline mean & 61 \\
\hline range & $26-78$ \\
\hline FIGO-Stage & 1 \\
\hline II & 1 \\
\hline III & 29 \\
\hline IV & 6 \\
\hline
\end{tabular}

\section{Histologic subtype}

\begin{tabular}{cc}
\hline serous & 31 \\
\hline endometriod & 1 \\
\hline clear cell & 1 \\
\hline undifferentiated & 4 \\
\hline
\end{tabular}

\section{Grading}

\begin{tabular}{cc}
\hline 1 & 0 \\
\hline 2 & 9 \\
\hline not determined/unknown & 27 \\
\hline Lymph node metastasis & 1 \\
\hline pN0 & 11 \\
\hline pN1 & 18 \\
\hline
\end{tabular}


Table 1: Patient characteristics (Continued)

\begin{tabular}{|c|c|}
\hline$N X$ & 8 \\
\hline \multicolumn{2}{|l|}{ Perioperative Ascites } \\
\hline$<500 \mathrm{ml}$ & 15 \\
\hline$>500 \mathrm{ml}$ & 21 \\
\hline not determined & 1 \\
\hline \multicolumn{2}{|l|}{$\begin{array}{l}\text { Residual tumor after } \\
\text { surgery }\end{array}$} \\
\hline microscopic & 22 \\
\hline macroscopic & 14 \\
\hline not determined & 1 \\
\hline \multicolumn{2}{|l|}{ Survival (months) } \\
\hline \multicolumn{2}{|c|}{ progression-free survival } \\
\hline mean & 20 \\
\hline median & 16 \\
\hline range & $2-71$ \\
\hline \multicolumn{2}{|l|}{ overall survival } \\
\hline mean & 36 \\
\hline median & 32 \\
\hline range & $8-98$ \\
\hline
\end{tabular}

(during the first follow-up visit 3 months after the last cycle of chemotherapy).

After centrifugation at $3400 \mathrm{rpm}$ for $10 \mathrm{~min}$, the supernatants were stored at $-20^{\circ} \mathrm{C}$ before use.

Quantitative analysis of serum VEGF-165 and TIMP-1 levels Serum VEGF-165 and TIMP-1 were quantified by commercially available ELISA (Siemens Healthcare Diagnostics, Tarrytown, USA). The serum samples and controls were diluted 1:10 (VEGF-165) and 1:50 (TIMP-1) with sample diluent buffer (containing bovine serum albumin, buffer salts and $0.09 \%$ sodium acide). One hundred microliters of the standards, diluted control samples and diluted serum samples were dispensed into 96-well plates (coated with an anti-human monoclonal antibody) and incubated for 1.5 hours at $37^{\circ} \mathrm{C}$ (VEGF-165) or $30 \mathrm{~min}$ utes at room temperature (TIMP-1). Wells were washed and one hundred microliters of the detection antibody (containing biotinylated anti-VEGF-165 monoclonal antibody or alkaline phosphatase-labeled anti-TIMP-1 antibody, respectively) were added.

VEGF-165 plates were incubated for one hour at $37^{\circ} \mathrm{C}$, washed and further incubated with one hundred microliters of streptavidin alkaline-phosphatase-labeled conjugate for one hour at room temperature. After washing, one hundred microliters of chromogenic substrate (BluePhos substrate) were added for 45 minutes at room temperature. The reaction was stopped with one hundred microliters EDTA-stop solution and absorbance was read at $650 \mathrm{~nm}$ by an automated plate-reader (Tecan, Crailsheim, Germany).

TIMP-1 plates were incubated for 30 minutes at room temperature. After washing, one hundred microliters of chromogenic pNPP-substrate was added for 25 minutes at room temperature in the dark. The reaction was stopped with one hundred microliters of EDTA-stop solution and absorbance was read at $405 \mathrm{~nm}$ by automated plate-reader (Tecan, Crailsheim, Germany).

The VEGF-165 and TIMP-1 concentration was estimated from the standard curve. Each sample, standard and control were analyzed in duplicate.

\section{Quantitative analysis of CA-125}

CA-125 serum levels were quantified using the secondgeneration electrochemiluminescence immunoassay (ECLIA) and the Roche Modular Analytics E170 system (Elecsys module, Roche Diagnostics, Mannheim, Germany) with $20 \mu \mathrm{l}$ serum samples.

\section{Statistical analysis}

All statistical analyses were conducted using SPSS software version 15.0 (SPSS Inc., Chicago, IL, USA). Changes in the serum level of each marker during therapy were calculated separately using the Wilcoxon test comparing paired samples at successive time points for individual patients.

Correlations between serum CA-125, VEGF-165 and TIMP-1 concentrations and tumor characteristics were calculated by Chi-square tests. For this purpose, cases were divided into two groups of equal size for each marker at each time-point using the median value as cutoff. The resulting groups were compared regarding the following parameters: age: $<61$ years versus 61 years and older; ascites: $<500 \mathrm{ml}$ versus $>500 \mathrm{ml}$; residual tumor 
after surgery: microscopic versus macroscopic; lymph node status: no metastasis versus lymph-node metastasis; grading: G2 versus G3. Correlations between serum VEGF-165 and TIMP-1 concentrations and treatment response according to $\mathrm{CA}-125$ decrease were evaluated by pair wise Pearson-correlations, assessing the coherence of continuous serum values of VEGF-165 and TIMP-1 and the relative decrease of CA-125 during therapy.

Kaplan-Meier analysis of progression-free survival (PFS) and overall survival (OS) was performed using the same groups. Survival probabilities were compared with the log-rank test. All tests were performed at a significance level of $\mathrm{p}=0.05$.

\section{Results}

Patients

A total of 37 patients were included in this study; detailed characteristics are listed in Table 1 . All patients underwent radical surgery including hysterectomy, bilateral salpingo-oophorectomy, appendectomy, infragastric omentectomy and systematic pelvic and paraaortic lymphadenectomy as well as resection of all visible tumor. In the majority of patients, complete debulking could be achieved (22 patients with microscopic residual tumor). All patients received platinum based first-line combination-chemotherapy. According to a decrease in CA-125 serum concentrations, all patients responded to first-line treatment except for one (median decrease in CA-125 was $95 \%$ (range $54 \%-100 \%$ ). Median follow up time was 29 months. In the study cohort, progression free survival ranged between 2 and 71 months with a median of 17 months; median overall survival was 44 months and ranged from 6-97 months.

\section{Serum concentration of CA-125, TIMP-1 and VEGF-165 duringfirst-line therapy}

Serum concentrations of CA-125, VEGF-165 and TIMP1 at the respective time-points are listed in Table 2. CA125 decreased significantly after surgery whereas the serum concentrations of TIMP-1 and VEGF-165 increased (Figure 1). During first-line chemotherapy the serum concentrations of CA-125, TIMP-1 and VEGF-165 decreased significantly compared to the previous timepoint. Further significant decrease after the end of chemotherapy was only observed for CA-125, while TIMP-1 and VEGF-165 remained unchanged. Compared to initial serum levels before surgery, CA-125, TIMP-1 and VEGF165 during and after chemotherapy also decreased significantly (during chemotherapy: $\mathrm{p}<0.001, \mathrm{p}=0.002$, $\mathrm{p}=$ 0.026 and after Chemotherapy: $\mathrm{p}<0.001, \mathrm{p}<0.001, \mathrm{p}=$ 0.001 , respectively). Linked data for the different markers in each patient are presented in Figure 2.

Correlation between serum concentration of CA-125, TIMP1 and VEGF-165 and clinicopathological factors, response, progression and survival

The serum values of each marker were divided in two groups (high and low) at each time-point using the median as cut-off value. Correlations between CA-125, TIMP-1 and VEGF-165 and progression and survival are listed in Table 3. Correlations between serum markers and clinicopathological parameters are listed in Table 4. Correlations between serum VEGF-165 and TIMP-1 concentrations and treatment response according to CA-125 are shown in Table 5.

High serum concentrations of CA-125 before surgery were significantly associated with age $(p=0.046)$ and large ascites volume $(\mathrm{p}=0.004)$. Increased CA-125 after debulking surgery was associated with improved overall survival ( $\mathrm{p}=0.033)$ and low CA-125 after chemotherapy was associated with improved progression-free ( $\mathrm{p}<$ 0.001 ) and overall survival ( $\mathrm{p}=0.002$, Figure 3 ).

High TIMP-1 concentration after chemotherapy was associated with decreased overall survival $(\mathrm{p}=0.007)$ and patients with large ascites volume had higher TIMP-1 concentrations at this time point $(\mathrm{p}=0.032)$.

High VEGF-165 before ( $\mathrm{p}=0.043$ ) as well as after chemotherapy $(p=0.006)$ was associated with decreased progression-free survival, while high serum-concentra-

Table 2: Serum concentrations of CA-125, TIMP-1 and VEGF at different time-points during therapy

\begin{tabular}{|c|c|c|c|c|c|c|c|c|c|c|c|c|}
\hline & \multicolumn{3}{|c|}{ Before surgery } & \multicolumn{3}{|c|}{ After surgery/before CTX } & \multicolumn{3}{|c|}{ during CTX } & \multicolumn{3}{|c|}{ after CTX } \\
\hline & mean & median & range & mean & median & range & mean & median & range & mean & median & range \\
\hline $\begin{array}{l}\text { CA-125 } \\
{[\mathrm{kU} / \mathrm{L}]}\end{array}$ & 1948 & 413 & $\begin{array}{c}20- \\
20880\end{array}$ & 325 & 84 & $15-5965$ & 113 & 21 & $6-2562$ & 72 & 15 & $5-1429$ \\
\hline $\begin{array}{l}\text { TIMP-1 } \\
{[\mathrm{ng} / \mathrm{mL}]}\end{array}$ & 451 & 403 & $273-887$ & 573 & 529 & $\begin{array}{l}323- \\
1000\end{array}$ & 377 & 351 & 204-616 & 371 & 333 & $209-990$ \\
\hline $\begin{array}{l}\text { VEGF } \\
{[\mathrm{pg} / \mathrm{mL}]}\end{array}$ & 231 & 171 & $25-791$ & 355 & 272 & $85-1133$ & 176 & 139 & $11-558$ & 192 & 147 & $11-960$ \\
\hline
\end{tabular}



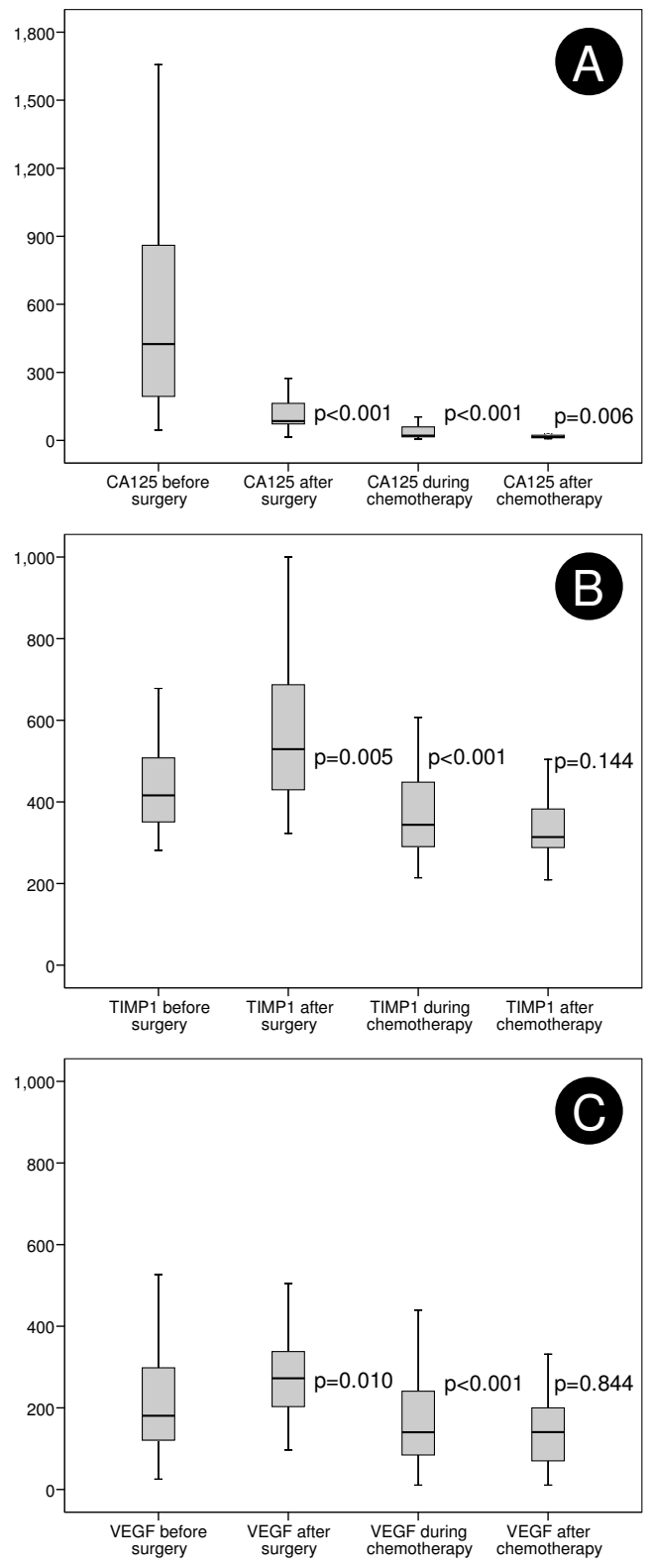

Figure 1 CA-125 [kU/L] (A), TIMP-1 [ng/L] (B) and VEGF [pg/L] (C) before and after surgery (=before chemotherapy) and during and after chemotherapy (Wilcoxon Tests comparing paired samples at successive time points for individual patients).

tion of VEGF-165 after chemotherapy was also associated with decreased overall survival $(p=0.02)$.

CA-125 concentration before surgery was inversely correlated with VEGF-165 concentration before surgery $(\mathrm{r}=-0.460 ; \mathrm{p}=0.01)$. No inter-marker-correlation was observed for the other factors except for a constant correlation between VEGF-165 and TIMP-1 before surgery ( $\mathrm{r}$ $=0.467 ; \mathrm{p}=0.008)$, after surgery $(\mathrm{r}=0.522 ; \mathrm{p}=0.002)$,

during chemotherapy $(\mathrm{r}=0.437 ; \mathrm{p}=0.009)$ and after chemotherapy $(r=0.408 ; p=0.017)$.

\section{Discussion}

To investigate the role of new serologic biomarkers in therapy monitoring and to determine their potential prognostic significance in ovarian cancer, TIMP-1, VEGF-165 and CA-125 were analyzed in 148 serum samples from 37 patients with epithelial ovarian cancer. We could demonstrate for the first-time that changes of VEGF-165 and TIMP-1 during first-line therapy of ovarian cancer are substantial and closely correlated. In addition, we found a potential prognostic and predictive role for TIMP-1 and VEGF-165.

Biomarkers play an important role in the management of ovarian cancer in several aspects. These include monitoring response to treatment, estimating prognosis and predicting response to specific drugs. Of all serologic markers, CA-125 is best established in ovarian cancer. In the follow-up of patients, rising serum concentrations correlate with disease progression in approximately $90 \%$ of cases [14]. It can also be used as a surrogate marker for response to chemotherapy, as a decrease in CA-125 by $50-75 \%$ correlated with response in several trials [17]. In the current study, we used CA-125 as 'benchmark biomarker' for comparison with new potential markers. As expected, CA-125 levels were high before surgery and decreased substantially during first-line therapy (Table 2, Figure 1). It was significantly associated with ascites volume ( $\mathrm{p}=0.004$, Table 3 ), a correlation that has previously been described for ovarian cancer as well as other malignancies [18]. We observed no correlation between preoperative CA-125 and survival but a weak, yet significant positive correlation between elevated pre-chemotherapeutic CA-125 and overall survival ( $\mathrm{p}=0.033)$. This correlation might just reflect the controversial role of pretreatment CA-125 in ovarian cancer: Some studies found a prognostic relevance while others failed to demonstrate this impact $[11,19,20]$. Due to these inconclusive findings, pre-treatment CA-125 has currently no clinical role before initiation of first-line therapy. Patients with low serum CA-125 at the end of first-line therapy had a favourable progression-free $(p<0.001)$ and overall survival ( $p=0.002$, Figure 3 ). Our results are consistent with other studies and confirm the utility of CA-125 as marker for ovarian cancer surveillance $[11,21]$. However, CA-125 has several limitations. Up to $20 \%$ of ovarian cancers are CA-125 negative despite substantial tumor burden [22]. In addition, more than $50 \%$ of patients with normalized CA-125 at the end of therapy still have persistent disease [23]. Finally, rising CA-125 does not always precede disease recurrence, thus, additional serum markers are required. 

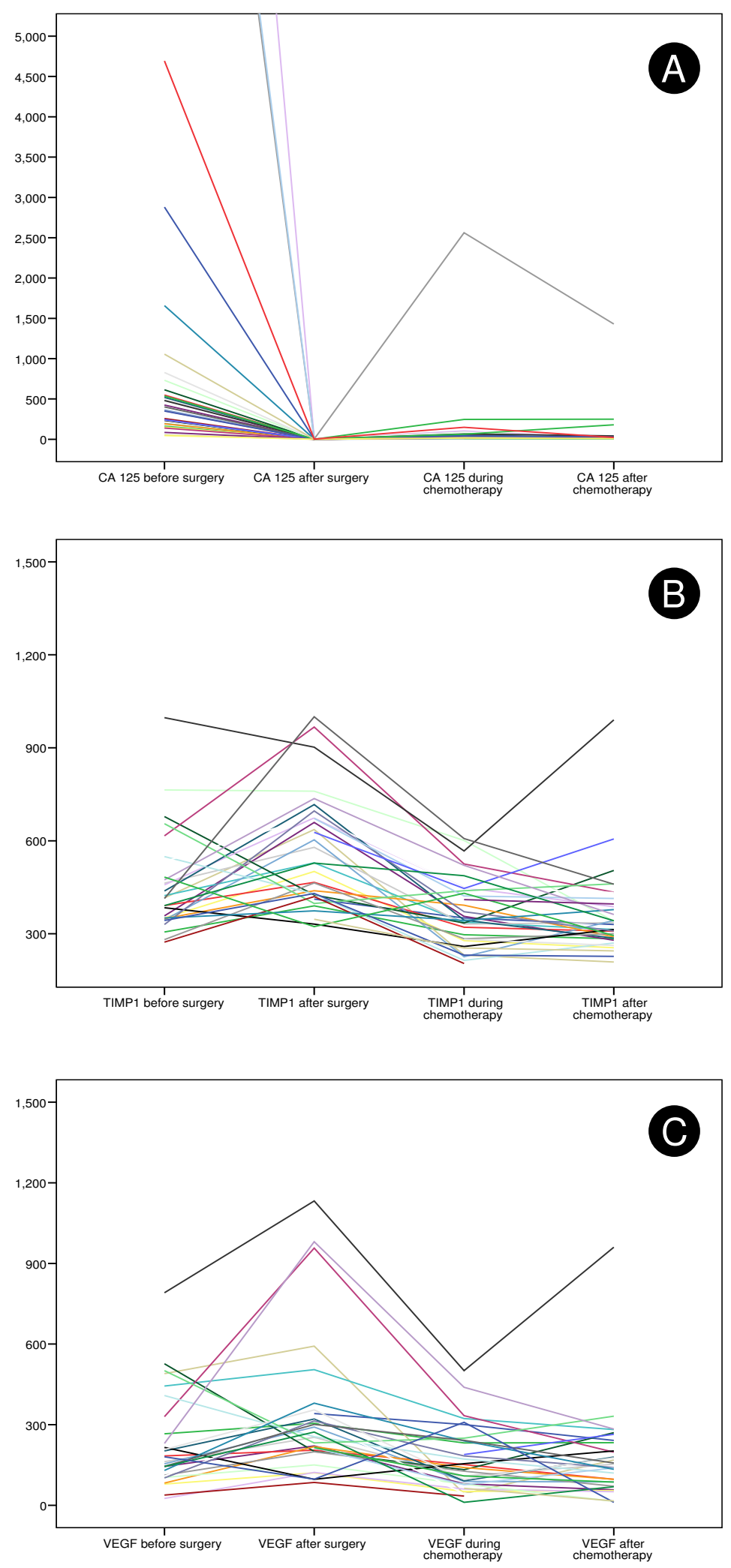

Figure 2 CA-125 [kU/L] (A), TIMP-1 [ng/L] (B) and VEGF [pg/L] (C) before and after surgery (=before chemotherapy) and during and after chemotherapy presented as linked data for each patient. 
Table 3: Correlations between serum concentration of CA-125, TIMP-1 and VEGF and survival

\begin{tabular}{|c|c|c|c|c|}
\hline & PFS & & os & \\
\hline & p-value & $+/-$ & p-value & $+/-$ \\
\hline CA-125 before surgery & 0.593 & . & 0.629 & . \\
\hline CA-125 before CTX & 0.725 & . & $0.033^{*}$ & - \\
\hline CA-125 during CTX & 0.627 & . & 0.308 & . \\
\hline CA-125 after CTX & $<0.001$ & + & $0.002^{*}$ & + \\
\hline TIMP-1 before surgery & 0.534 & . & 0.195 & . \\
\hline TIMP-1 before CTX & 0.499 & . & 0.980 & . \\
\hline TIMP-1 during CTX & 0.781 & . & 0.380 & . \\
\hline TIMP-1 after CTX & 0.152 & . & 0.007 & + \\
\hline VEGF before surgery & 0.352 & . & 0.302 & . \\
\hline VEGF before CTX & 0.043 & + & 0.230 & . \\
\hline VEGF during CTX & 0.946 & . & 0.496 & . \\
\hline VEGF after CTX & 0.006 & + & 0.023 & + \\
\hline
\end{tabular}

Angiogenesis has been established as a crucial feature of tumor development, growth and spread [24]. VEGF is the most prominent angiogenic molecule and has been shown to parallel tumor growth and metastasis in various cancer types [25] and is currently the most promising target for anti-angiogenic therapy in ovarian cancer [6-8]. In contrast to other targeted therapies like trastuzumab for breast cancer [26], no predictive marker has been established so far for bevacizumab treatment. VEGF could play a role in this situation. Although there is abundant evidence that VEGF plays a central role in the development and growth of ovarian cancer, information regarding the clinical utility of serum VEGF levels is limited and inconclusive. VEGF has been detected in tissue and serum of patients with ovarian cancer [27-33]. It was shown that the serum levels of VEGF are significantly elevated in patients with epithelial ovarian cancer compared to levels in patients with benign disease [33]. In the largest published analysis of 314 patients with ovarian cancer, high preoperative VEGF serum concentrations were associated with decreased overall survival by multivariate analysis [31]. Several other studies produced conflicting results regarding the prognostic impact of serum VEGF [27,28,30,32,34-40]. However, the variation of serum VEGF values in the course of treatment has not been studied since many of these studies used 'pre-treatment' samples and did not separate between pre- and postoperative serum samples or clearly define time points of serum collection.

When comparing different study results there is a high variability of VEGF serum levels, which might be caused by differences in assay techniques (many assays have no specificity for different VEGF-isoforms), storage of specimens and the small number of samples analyzed in most 
Table 4: Correlations between serum concentration of CA-125, TIMP-1 and VEGF and clinicopathological factors

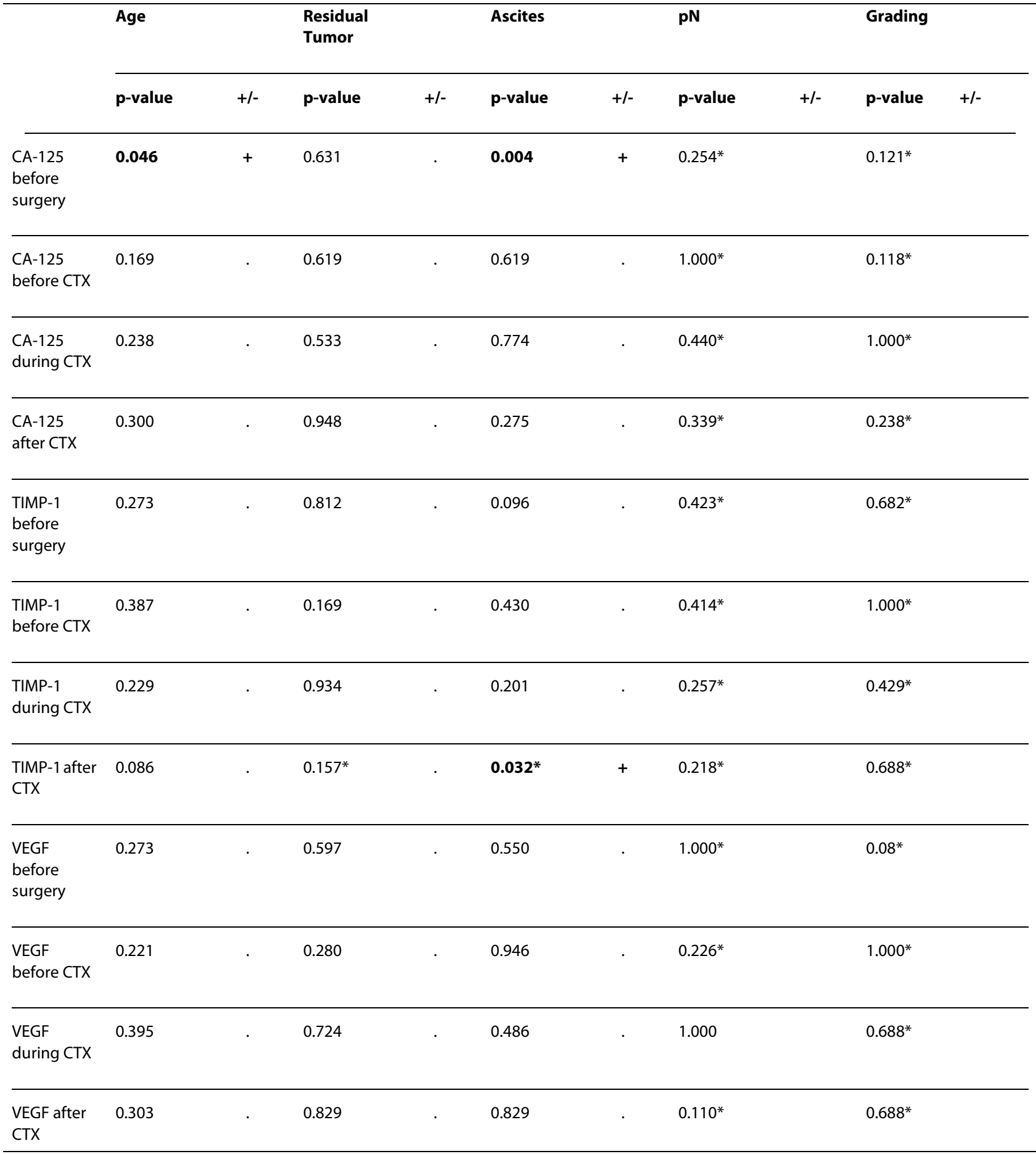

Correlations between serum concentration of CA-125, TIMP-1 and VEGF (below/above median) and clinicopathological factors. A positive correlation indicates a higher likelihood of an event. P-values from the Pearson-Chi'-Test and from Fisher's exact test ${ }^{*}$ ) are reported for binary correlations with age: $<61$ years versus 61 years or older; ascites: $<500 \mathrm{ml}$ versus $>500 \mathrm{ml}$; residual tumor after surgery: microscopic versus macroscopic; lymph node status: no metastasis versus lymph-node metastasis; grading: G2 versus G3. +/- indicates the direction of a significant correlation. 
Table 5: Correlations between serum concentrations of VEGF-165 and TIMP-1 and response to first-line treatment according to decrease of CA-125.

Response (\% decrease of CA-125)

p-value correlation coefficient $r$

\begin{tabular}{lll}
\hline TIMP-1 before surgery & 0.375 & 0.174 \\
\hline TIMP-1 before CTX & 0.150 & 0.265 \\
\hline TIMP-1 during CTX & 0.480 & 0.127 \\
\hline TIMP-1 after CTX & 0.554 & 0.107 \\
\hline VEGF before surgery & 0.725 & -0.07 \\
\hline VEGF before CTX & 0.729 & 0.065 \\
\hline VEGF during CTX & 0.414 & -0.147 \\
\hline VEGF after CTX & & \\
\hline
\end{tabular}

P-values according to the Pearson correlation coefficients using continous serum values and relative decrease of CA-125.

studies. Furthermore, there is no clearly defined 'cut-off' to classify serum VEGF concentrations as elevated or normal. This complicates cross trial comparison and was our rationale to use median values as 'cut-off' for the analyses. With this approach, pre- or postoperative VEGF-165 had no prognostic significance. In the current study, we observed a significant increase between preand postoperative serum VEGF-165 levels ( $p=0.01$, Figure 1, Table 2). Moreover, we found a significant consecutive decrease of serum VEGF-165 during chemotherapy ( $p<0.001)$. These results suggest that serum VEGF-165 may be helpful in therapy monitoring and surveillance of ovarian cancer patients and can provide additional information to CA-125 measurements. Given the high interstudy-variability of VEGF serum levels, a longitudinal measurement of individual patient levels might be a better approach than the assessment of absolute values at single time-points.

The prognostic potential of VEGF-165 levels after chemotherapy has also been described in a study evaluating the role of serum VEGF-165 in patients with complete response after first-line therapy [41]. These patients underwent second look surgery and women with persistent disease had higher VEGF serum levels. Taken together, these findings might add to the rationale of antiVEGF therapy after completion of surgical and cytostatic first-line therapy of ovarian cancer, a concept currently under investigation in large phase III trials [42].

In contrast to previous findings by $\mathrm{Li}$ et al. [34] and Oehler et al. [36] we observed an initial postoperative increase of VEGF-165 and consecutive decrease during and after chemotherapy. The large wound area and healing process after radical debulking surgery often including extensive peritonectomy could explain the increase of angiogenic factors, as previously described for other malignancies [43]. Another reason for this difference might be the delayed collection of blood samples in the other series. Oehler et al. collected samples 4 weeks after surgery, a time at which most healing processes are already completed whereas in our study postoperative serum was collected within the first 7 days after surgery.

Matrix Metalloproteinases (MMPs) play a key role in invasion and metastasis of cancer cells. They are able to degrade extracellular matrix and aid angiogenesis [44]. MMPs can be regulated by their inhibitors, the tissue inhibitor of metalloproteinases (TIMPs) [45]. In addition to this regulatory role, TIMPs possess pro-tumorigenic and metastatic activity [46]. Increased expression of TIMP-1 has been associated with unfavourable outcome in several tumor types $[47,48]$. For ovarian cancer, conflicting results have been reported showing both up- and downregulation of TIMP-1 [49-51]. Rauvala et al. studied the level of TIMP-1 in preoperative serum of patients 

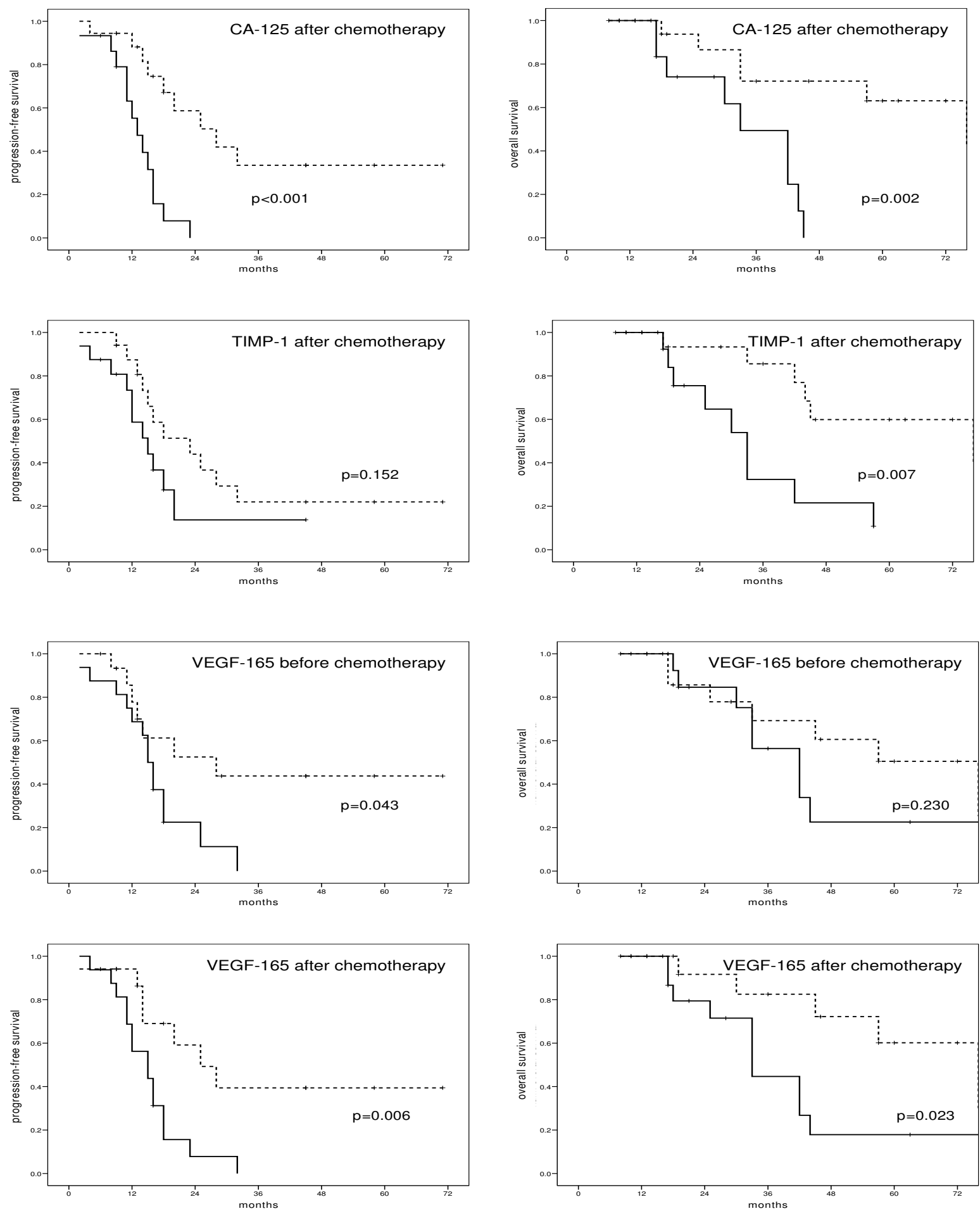

Figure 3 Kaplan-Meier plots of progression-free survival (left) and overall survival (right) for serum concentrations of CA-125 after chemotherapy, TIMP-1 after chemotherapy, VEGF-165 before chemotherapy and VEGF-165 after chemotherapy. Dotted line: below median; solidline: above median. 
with ovarian cancer [52]. They found an elevated preoperative serum TIMP-1 to be associated with unfavourable clinical outcome, as previously suggested in a smaller study by Manenti et al. [40]. A negative prognostic impact of serum TIMP-1 has also been observed in breast cancer, colorectal cancer and other malignancies [53,54]. In the current study, we observed no correlation between preor postoperative serum concentrations of TIMP-1 and outcome (Table 3). However, low serum concentration at the end of chemotherapy was associated with improved overall survival ( $p=0.007)$. Of note, TIMP-1 serum levels were closely correlated with VEGF-165 at all time-points (Figure 1 and 2). This could reflect common regulatory mechanisms and confirm the biological connection of both factors in ovarian cancer, leading to degradation of basement membranes and extracellular matrix as well as neovascularization.

In contrast to CA-125, a "normal value" could not be defined for TIMP-1 and VEGF-165 and different cut-off values have been used in previous studies $[18,19,25,27$ 41,47,53-56]. We therefore assume that a longitudinal measurement of individual patient levels - using each patient as their own control - might be a better approach than the assessment of absolute values at single timepoints.

Limitations of our study are the relatively small number of patients, its mono-centric design and the fact that samples were not strictly collected in consecutive patients, leading to a possible selection bias. However, the uniform treatment and high rate of patients with optimal surgical cytoreduction followed by platinum based combination chemotherapy might be a strength of this study. Biological markers are more likely to be detectable in patients without residual tumor burden, the most important unfavourable prognostic factor.

\section{Conclusion}

This study is the first comprehensive longitudinal analysis of serum VEGF-165 and TIMP-1 in patients with ovarian cancer. It demonstrates that these markers change substantially during first-line therapy, are not correlated with CA-125 and might have prognostic relevance, suggesting a potential role in the surveillance of women with ovarian cancer. To further understand this role, the evaluation of TIMP-1 and VEGF in the context of prospective clinical trials is highly desirable.

\section{Competing interests}

ELISA kits were provided at no cost by Siemens Medical Solutions Diagnostics. One co-author (WC) is employee of Siemens Medical Solutions Diagnostics; the other authors declare that they have no competing interests.

\section{Authors' contributions}

SM participated in the design and coordination of the study, drafted the manuscript and participated in the statistical analysis. LW participated in the design and coordination of the study, drafted the manuscript and participated in the statistical analysis. CE participated in the design of the study and performed the statistical analysis and helped to draft the manuscript. JS participated in the design and coordination of the study. WC participated in the design of the study and helped to draft the manuscript. FJ participated in the design and coordination of the study and interpretation of the results. KML carried out the immunoassays, helped to draft the manuscript and participated in the statistical analysis. VM participated in the design and coordination of the study, drafted the manuscript and participated in the interpretation of the results. All authors read and approved the final manuscript.

\section{Acknowledgements}

We thank Mrs. S. Krenkel for excellent technical assistance as well as Drs. C. Utler, T. Osterholz and S. Jung for invaluable help with evaluation of clinical data and follow-up. This study was funded by internal departmental sources, ELISA kits were provided at no cost by Siemens Medical Solutions Diagnostics.

\section{Author Details}

'Department of Gynecology and Gynecologic Oncology, University Medical Center Hamburg-Eppendorf, Hamburg, Germany, ${ }^{2}$ Department of Medical Biometry and Epidemiology, University Medical Center Hamburg-Eppendorf, Hamburg, Germany, ${ }^{3}$ Oncogene Science/Siemens Health Care DX, Cambridge, MA, USA and ${ }^{4}$ Department of Gynecology, Asklepios Klinik Nord - Heidberg, Hamburg, Germany

Received: 18 September 2009 Accepted: 13 April 2010

Published: 13 April 2010

\section{References}

1. American-Cancer-Society: Cancer Facts and Figures. Atlanta: American Cancer Society; 2008.

2. Cannistra SA: Cancer of the ovary. NEngl J Med 2004, 351(24):2519-2529.

3. du Bois A, Luck HJ, Meier W, Adams HP, Mobus V, Costa S, Bauknecht T, Richter B, Warm M, Schroder W, et al: A randomized clinical trial of cisplatin/paclitaxel versus carboplatin/paclitaxel as first-line treatment of ovarian cancer. J Nat/ Cancer Inst 2003, 95(17):1320-1329.

4. Bookman MA, Brady MF, McGuire WP, Harper PG, Alberts DS, Friedlander M, Colombo N, Fowler JM, Argenta PA, De Geest K, et al:: Evaluation of new platinum-based treatment regimens in advanced-stage ovarian cancer: a Phase III Trial of the Gynecologic Cancer Intergroup. J Clin Oncol 2009, 27(9):1419-1425.

5. Yap TA, Carden CP, Kaye SB: Beyond chemotherapy: targeted therapies in ovarian cancer. Nat Rev Cancer 2009, 9(3):167-181.

6. Burger RA, Sill MW, Monk BJ, Greer BE, Sorosky Jl: Phase II trial of bevacizumab in persistent or recurrent epithelial ovarian cancer or primary peritoneal cancer: a Gynecologic Oncology Group Study. Clin Oncol 2007, 25(33):5165-5171.

7. Cannistra SA, Matulonis UA, Penson RT, Hambleton J, Dupont J, Mackey H, Douglas J, Burger RA, Armstrong D, Wenham R, et al:: Phase II study of bevacizumab in patients with platinum-resistant ovarian cancer or peritoneal serous cancer. J Clin Oncol 2007, 25(33):5180-5186.

8. Garcia AA, Hirte H, Fleming G, Yang D, Tsao-Wei DD, Roman L, Groshen S, Swenson S, Markland F, Gandara D, et al: : Phase II clinical trial of bevacizumab and low-dose metronomic oral cyclophosphamide in recurrent ovarian cancer: a trial of the California, Chicago, and Princess Margaret Hospital phase II consortia. J Clin Onco/ 2008, 26(1):76-82.

9. Spannuth WA, Sood AK, Coleman RL: Angiogenesis as a strategic target for ovarian cancer therapy. Nat Clin Pract Oncol 2008, 5(4):194-204.

10. du Bois A, Reuss A, Pujade-Lauraine E, Harter P, Ray-Coquard I, Pfisterer J: Role of surgical outcome as prognostic factor in advanced epithelial ovarian cancer: A combined exploratory analysis of 3 prospectively randomized phase 3 multicenter trials: by the Arbeitsgemeinschaft Gynaekologische Onkologie Studiengruppe Ovarialkarzinom (AGOOVAR) and the Groupe d'Investigateurs Nationaux Pour les Etudes des Cancers de l'Ovaire (GINECO). Cancer 2009, 115(6):1234-1244.

11. Gadducci A, Cosio S, Tana R, Genazzani AR: Serum and tissue biomarkers as predictive and prognostic variables in epithelial ovarian cancer. Crit Rev Oncol Hematol 2009, 69(1):12-27.

12. Mahner S, Baasch C, Schwarz J, Hein S, Wolber L, Janicke F, MildeLangosch $\mathrm{K}$ : C-Fos expression is a molecular predictor of progression and survival in epithelial ovarian carcinoma. Br J Cancer 2008, 99(8):1269-1275. 
13. Bast RC Jr, Klug TL, St John E, Jenison E, Niloff JM, Lazarus H, Berkowitz RS, Leavitt T, Griffiths $C T$, Parker L, et al:: A radioimmunoassay using a monoclonal antibody to monitor the course of epithelial ovarian cancer. N Engl J Med 1983, 309(15):883-887.

14. Bast RC Jr, Badgwell D, Lu Z, Marquez R, Rosen D, Liu J, Baggerly KA, Atkinson EN, Skates S, Zhang Z, et al:: New tumor markers: CA125 and beyond. Int J Gynecol Cancer 2005, 15(Suppl 3):274-281.

15. Hicklin DJ, Ellis LM: Role of the vascular endothelial growth factor pathway in tumor growth and angiogenesis. J Clin Oncol 2005, 23(5):1011-1027.

16. Moller Sorensen N, Vejgaard Sorensen I, Ornbjerg Wurtz S, Schrohl AS, Dowell B, Davis G, Jarle Christensen I, Nielsen HJ, Brunner N: Biology and potential clinical implications of tissue inhibitor of metalloproteinases1 in colorectal cancer treatment. Scand J Gastroenterol 2008, 43(7):774-786

17. Rustin GJ, Bast RC Jr, Kelloff GJ, Barrett JC, Carter SK, Nisen PD, Sigman CC, Parkinson DR, Ruddon RW: Use of CA-125 in clinical trial evaluation of new therapeutic drugs for ovarian cancer. Clin Cancer Res 2004, 10(11):3919-3926

18. Topalak O, Saygili U, Soyturk M, Karaca N, Batur Y, Uslu T, Erten O: Serum, pleural effusion, and ascites CA-125 levels in ovarian cancer and nonovarian benign and malignant diseases: a comparative study. Gynecol Oncol 2002, 85(1):108-113.

19. Makar AP, Kristensen GB, Kaern J, Bormer OP, Abeler VM, Trope CG Prognostic value of pre- and postoperative serum CA 125 levels in ovarian cancer: new aspects and multivariate analysis. Obstet Gynecol 1992, 79(6):1002-1010.

20. Rustin GJ, Gennings JN, Nelstrop AE, Covarrubias H, Lambert HE, Bagshawe KD: Use of CA-125 to predict survival of patients with ovarian carcinoma. North Thames Cooperative Group. J Clin Oncol 1989, 7(11):1667-1671.

21. Prat A, Parera M, Peralta S, Perez-Benavente MA, Garcia A, Gil-Moreno A, Martinez-Palones JM, Roxana I, Baselga J, Del Campo JM: Nadir CA-125 concentration in the normal range as an independent prognostic factor for optimally treated advanced epithelial ovarian cancer. Ann Oncol 2008, 19(2):327-331.

22. Rosen DG, Wang L, Atkinson JN, Yu Y, Lu KH, Diamandis EP, Hellstrom I, Mok SC, Liu J, Bast RC Jr: Potential markers that complement expression of CA125 in epithelial ovarian cancer. Gynecol Oncol 2005, 99(2):267-277.

23. Rubin SC, Hoskins WJ, Hakes TB, Markman M, Reichman BS, Chapman D, Lewis JL Jr: Serum CA 125 levels and surgical findings in patients undergoing secondary operations for epithelial ovarian cancer. Am J Obstet Gynecol 1989, 160(3):667-671.

24. Folkman J: Tumor angiogenesis: therapeutic implications. N Eng/ J Med 1971, 285(21):1182-1186.

25. Salven P, Manpaa H, Orpana A, Alitalo K, Joensuu H: Serum vascular endothelial growth factor is often elevated in disseminated cancer. Clin Cancer Res 1997, 3(5):647-651.

26. Pegram MD, Konecny G, Slamon DJ: The molecular and cellular biology of HER2/neu gene amplification/overexpression and the clinical development of herceptin (trastuzumab) therapy for breast cancer. Cancer Treat Res 2000, 103:57-75.

27. Chen CA, Cheng WF, Lee CN, Chen TM, Kung CC, Hsieh FJ, Hsieh CY: Serum vascular endothelial growth factor in epithelial ovarian neoplasms: correlation with patient survival. Gynecol Oncol 1999, 74(2):235-240

28. Cooper BC, Ritchie JM, Broghammer CL, Coffin J, Sorosky Jl, Buller RE, Hendrix MJ, Sood AK: Preoperative serum vascular endothelial growth factor levels: significance in ovarian cancer. Clin Cancer Res 2002, 8(10):3193-3197.

29. Duncan TJ, Al-Attar A, Rolland P, Scott IV, Deen S, Liu DT, Spendlove I, Durrant LG: Vascular endothelial growth factor expression in ovarian cancer: a model for targeted use of novel therapies? Clin Cancer Res 2008, 14(10):3030-3035

30. Gadducci A, Ferdeghini M, Fanucchi A, Annicchiarico C, Ciampi B, Prontera C, Genazzani AR: Serum preoperative vascular endothelial growth factor (VEGF) in epithelial ovarian cancer: relationship with prognostic variables and clinical outcome. Anticancer Res 1999, 19(2B):1401-1405.

31. Hefler LA, Zeillinger R, Grimm C, Sood AK, Cheng WF, Gadducci A, Tempfer $C B$, Reinthaller $A$ : Preoperative serum vascular endothelial growth factor as a prognostic parameter in ovarian cancer. Gynecol Oncol 2006, 103(2):512-517.

32. Tempfer C, Obermair A, Hefler L, Haeusler G, Gitsch G, Kainz C: Vascular endothelial growth factor serum concentrations in ovarian cancer. Obstet Gynecol 1998, 92(3):360-363.

33. Yamamoto S, Konishi I, Mandai M, Kuroda H, Komatsu T, Nanbu K, Sakahara H, Mori T: Expression of vascular endothelial growth factor (VEGF) in epithelial ovarian neoplasms: correlation with clinicopathology and patient survival, and analysis of serum VEGF levels. Br J Cancer 1997, 76(9):1221-1227.

34. Li L, Wang L, Zhang W, Tang B, Zhang J, Song H, Yao D, Tang Y, Chen $X$ Yang Z, et al:: Correlation of serum VEGF levels with clinical stage, therapy efficacy, tumor metastasis and patient survival in ovarian cancer. Anticancer Res 2004, 24(3b):1973-1979.

35. Harlozinska A, Sedlaczek P, Kulpa J, Grybos M, Wojcik E, Van Dalen A, Einarsson R: Vascular endothelial growth factor (VEGF) concentration in sera and tumor effusions from patients with ovarian carcinoma. Anticancer Res 2004, 24(2C):1149-1157.

36. Oehler MK, Caffier H: Prognostic relevance of serum vascular endothelial growth factor in ovarian cancer. Anticancer Res 2000, 20(6D):5109-5112.

37. Kraft A, Weindel K, Ochs A, Marth C, Zmija J, Schumacher P, Unger $C$, Marme D, Gastl G: Vascular endothelial growth factor in the sera and effusions of patients with malignant and nonmalignant disease. Cancer 1999, 85(1):178-187.

38. Rudlowski C, Pickart AK, Fuhljahn C, Friepoertner T, Schlehe B, Biesterfeld $\mathrm{S}$, Schroeder W: Prognostic significance of vascular endothelial growth factor expression in ovarian cancer patients: a long-term follow-up. Int J Gynecol Cancer 2006, 16(Suppl 1):183-189.

39. Dehaven K, Taylor DD, Gercel-Taylor C: Comparison of serum vascular endothelial growth levels between patients with and without ovarian malignancies. Int J Gynecol Cancer 2002, 12(6):715-719.

40. Manenti L, Paganoni P, Floriani I, Landoni F, Torri V, Buda A, Taraboletti G, Labianca R, Belotti D, Giavazzi R: Expression levels of vascular endothelial growth factor, matrix metalloproteinases 2 and 9 and tissue inhibitor of metalloproteinases 1 and 2 in the plasma of patients with ovarian carcinoma. Eur J Cancer 2003, 39(13):1948-1956.

41. Alvarez Secord A, Sayer R, Snyder SA, Broadwater G, Rodriguez GC, Berchuck A, Blackwell K: The relationship between serum vascular endothelial growth factor, persistent disease, and survival at secondlook laparotomy in ovarian cancer. Gynecol Oncol 2004, 94(1):74-79.

42. Mabuchi S, Terai Y, Morishige K, Tanabe-Kimura A, Sasaki H, Kanemura M, Tsunetoh S, Tanaka Y, Sakata M, Burger RA, et al.: Maintenance treatment with bevacizumab prolongs survival in an in vivo ovarian cancer model. Clin Cancer Res 2008, 14(23):7781-7789.

43. Svendsen MN, Werther K, Nielsen HJ, Kristjansen PE: VEGF and tumour angiogenesis. Impact of surgery, wound healing, inflammation and blood transfusion. Scand J Gastroenterol 2002, 37(4):373-379.

44. Chambers AF, Matrisian LM: Changing views of the role of matrix metalloproteinases in metastasis. J Natl Cancer Inst 1997, 89(17):1260-1270.

45. Goldberg GI, Strongin A, Collier IE, Genrich LT, Marmer BL: Interaction of 92-kDa type IV collagenase with the tissue inhibitor of metalloproteinases prevents dimerization, complex formation with interstitial collagenase, and activation of the proenzyme with stromelysin. J Biol Chem 1992, 267(7):4583-4591.

46. Lambert E, Dasse E, Haye B, Petitfrere E: TIMPs as multifacial proteins. Crit Rev Oncol Hematol 2004, 49(3):187-198,

47. Gouyer V, Conti M, Devos P, Zerimech F, Copin MC, Creme E, Wurtz A, Porte H, Huet G: Tissue inhibitor of metalloproteinase 1 is an independent predictor of prognosis in patients with nonsmall cell lung carcinoma who undergo resection with curative intent. Cancer 2005, 103(8):1676-1684.

48. Zeng ZS, Cohen AM, Zhang ZF, Stetler-Stevenson W, Guillem JG: Elevated tissue inhibitor of metalloproteinase 1 RNA in colorectal cancer stroma correlates with lymph node and distant metastases. Clin Cancer Res 1995, 1(8):899-906.

49. Sakata K, Shigemasa K, Nagai N, Ohama K: Expression of matrix metalloproteinases (MMP-2, MMP-9, MT1-MMP) and their inhibitors (TIMP-1, TIMP-2) in common epithelial tumors of the ovary. Int $J$ Oncol 2000, 17(4):673-681 
50. Huang LW, Garrett AP, Bell DA, Welch WR, Berkowitz RS, Mok SC: Differential expression of matrix metalloproteinase- 9 and tissue inhibitor of metalloproteinase- 1 protein and mRNA in epithelial ovarian tumors. Gynecol Oncol 2000, 77(3):369-376.

51. Kikkawa F, Tamakoshi K, Nawa A, Shibata K, Yamagata S, Yamagata T, Suganuma N: Positive correlation between inhibitors of matrix metalloproteinase 1 and matrix metalloproteinases in malignant ovarian tumor tissues. Cancer Lett 1997, 120(1):109-115.

52. Rauvala M, Puistola U, Turpeenniemi-Hujanen T: Gelatinases and their tissue inhibitors in ovarian tumors; TIMP-1 is a predictive as well as a prognostic factor. Gynecol Oncol 2005, 99(3):656-663.

53. Lipton A, Leitzel K, Chaudri-Ross HA, Evans DB, Ali SM, Demers L, Hamer P, Brown-Shimer S, Pierce K, Gaur V, et al: Serum TIMP-1 and response to the aromatase inhibitor letrozole versus tamoxifen in metastatic breast cancer. J Clin Oncol 2008, 26(16):2653-2658.

54. Wurtz SO, Schrohl AS, Mouridsen H, Brunner N: TIMP-1 as a tumor marker in breast cancer--an update. Acta Oncol 2008, 47(4):580-590.

55. Hamer P, Bradley S, Gaur V, Carney W: An isoform-specific VEGF165 ELISA and increases in serum VEGF165 in colon cancer patients. American Association for Cancer Research Annual Meeting: Proceedings 2007

56. Holten-Andersen MN, Nielsen HJ, Sorensen S, Jensen V, Brunner N, Christensen IJ: Tissue inhibitor of metalloproteinases-1 in the postoperative monitoring of colorectal cancer. Eur J Cancer 2006, 42(12):1889-1896.

\section{Pre-publication history}

The pre-publication history for this paper can be accessed here: http://www.biomedcentral.com/1471-2407/10/139/prepub

doi: $10.1186 / 1471-2407-10-139$

Cite this article as: Mahner et al., TIMP-1 and VEGF-165 serum concentration during first-line therapy of ovarian cancer patients BMC Cancer 2010, 10:139

Submit your next manuscript to BioMed Central and take full advantage of:

- Convenient online submission

- Thorough peer review

- No space constraints or color figure charges

- Immediate publication on acceptance

- Inclusion in PubMed, CAS, Scopus and Google Scholar

- Research which is freely available for redistribution

Submit your manuscript at www.biomedcentral.com/submit
C) Biomed Central 